\title{
Bending Behavior on Beam with Supporting Part
}

\author{
Zefry Darmawan ${ }^{1}$, Dwi Hadi S ${ }^{1}$, Debrina Puspita A ${ }^{1}$, Shigeyuki Haruyama ${ }^{2}$, Oke Oktavianty ${ }^{1, *}$ \\ ${ }^{1}$ Department of Industrial Engineering, Brawijaya University, Indonesia \\ ${ }^{2}$ Graduate School of Management of Technology, Yamaguchi University, Japan
}

Received July 23, 2019; Revised October 1, 2019; Accepted December 23, 2019

Copyright $\bigcirc 2020$ by authors, all rights reserved. Authors agree that this article remains permanently open access under the terms of the Creative Commons Attribution License 4.0 International License

\begin{abstract}
Equipment used to help road users during road maintenance activities is called a flexible bridge. It helps maintain the accessible area of the road when repairs occur. Collapse has occurred sometimes at frame when bending load exceeds the yield strength. In addition to increase the ability of the structure and avoid buckling added a link as damper. Parameters of the absorber are stiffness rate, and elongation of link. A simple square tube beam model supported by a link was created to investigate the bending behavior using finite element analysis. The analysis result showed that beam supported by a link able to reduce buckling moreover provides longer curvature than beam without a link.
\end{abstract}

Keywords Flexible Bridge, Finite Element

\section{Introduction}

Nowadays many structural members are composed of various types of tubes. Rectangular tube is one of the commonly referred as supporting structure. Many researchers have studied experimentally and virtually using finite element about characteristic of deformation on rectangular tubes [1]-[4].

Plastic deformation of collapse mode on rectangular tubes was theoretically explored [1]. Kecman proposed a simple collapse mechanism using hinge moment and associated angle of rotation. A new collapse mechanism of rectangular section columns improved Kecman's theory
[5]. Axial compression of rectangular tube obtained as complex deformation mechanism around tube's web [6].

Numerous finite element analysis of rectangular tube to explore plastic deformation investigated widely [7]-[9]. Buckling behavior was observed as critical problem caused structural ruptures. Buckling was observed from flattening ratio which influenced most by geometrical shapes rather than material properties [10]. Flattening deformation influenced by ratio of thickness, length, and width of sidewall [8].

Supporting structure to increase buckling resistance of tube subjected to axial crushing and lateral bending was developed in many applications. A foam-filled thin-wall tube with various lateral graded thicknesses was applied in automobile components [11]. Due to localized deformation, the buckling resistance decrease sharply. Foam material was acting as support against buckling [12].

This study was focused on square tube structures using link as supporting part to reduce buckling. Supporting part was attached on end side of tube and fastened to rigid wall while the other side received bending momen. Elongation of supporting part investigated to observed buckling resistance of whole structure.

\section{Methodology}

Research model of square tube for bending analysis was built from thin-wall structure. Tube thickness $t$ was varied at web and the lid thickness $t$ ' set to five times of $t$ [13]. Dimension of C1 and C2 are equal to C (100mm), Figure 1 shows the square tube model. 


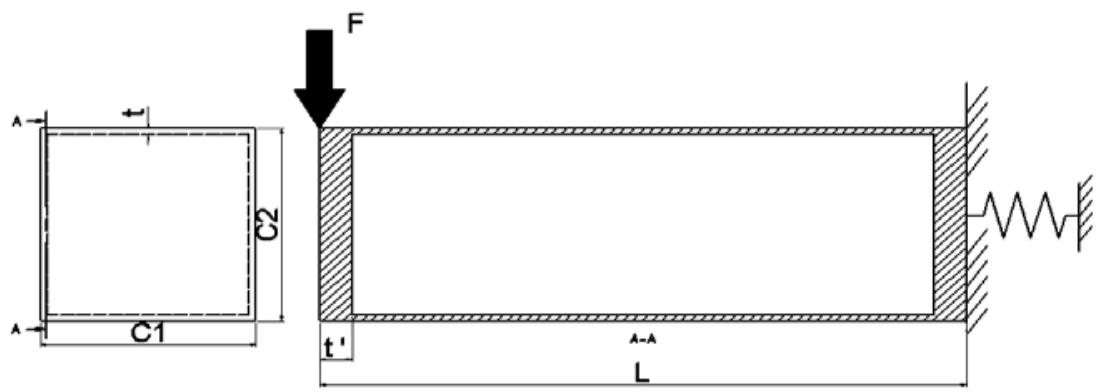

Figure 1. Square tube model

Material of square tube assumed bilinear isotropic hardening in uniaxial stress. Properties of stress-strain relationship followed rule (1) for elastic condition and rule (2) for plastic condition according bilinear law.

$$
\begin{gathered}
\sigma=\mathrm{E} \varepsilon \quad\left[\varepsilon<\frac{\sigma y}{E \varepsilon}\right] \\
\sigma=\sigma y+E h\left(\varepsilon-\frac{\sigma y}{E}\right) \quad\left[\varepsilon>\frac{\sigma y}{E \varepsilon}\right]
\end{gathered}
$$

Parameters and material properties of square tube are followed table 1

Table 1. Properties of square tube

\begin{tabular}{|c|c|}
\hline Properties & Value \\
\hline Length [L] (mm) & 1000 \\
\hline Width [C1=C2] (mm) & 100 \\
\hline Thickness [t] (mm) & 2 \\
\hline Modulus [E] (GPa) & 205.9 \\
\hline Poisson's ratio [v] & 0.3 \\
\hline Hardening ratio [Eh/E] & $1 / 100$ \\
\hline Yield stress [Y] (MPa) & 205.9 \\
\hline
\end{tabular}

Supporting part characteristic is according to figure 2 .

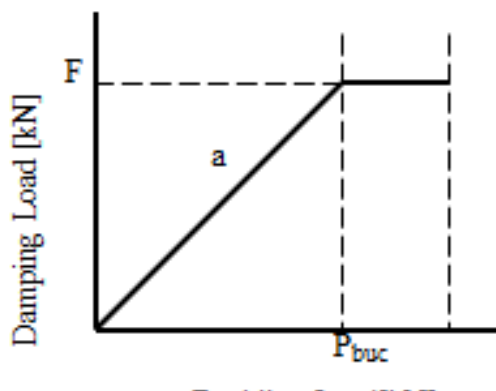

Figure 2. Supporting part characteristic [11]

Supporting part's characteristic is followed equation (3). This is assumed to be spring force according to Hooke's law.

$$
\begin{gathered}
F=a P_{\text {buc }}[K N] \\
P_{\text {buc }}=\sigma_{\text {buc }} . A
\end{gathered}
$$

Table 2. Supporting part parameters

\begin{tabular}{|c|c|}
\hline Parameter & Value \\
\hline Stiffness rate (a) & $0.2,0.4,0.6,0.8$ \\
\hline Shape factor (t/C) & 0,02 \\
\hline
\end{tabular}

Where $\mathrm{F}$ is damping load of supporting part, $\mathrm{P}_{\mathrm{buc}}$ is buckling load at square tube, and $\mathrm{A}$ is rectangular cross section of square tube.

\section{Result}

Finite element modelling was made by MSC Marc software to conduct analysis of bending square tube. Meshing type is quadrilateral, where 1 element consists of 4 nodes, element type of tube is 3D shell. Meshing size is $5 \times 5[\mathrm{~mm}]$. Maximum bending stress obtained from table 3 for square without damper and square tube with supporting part.

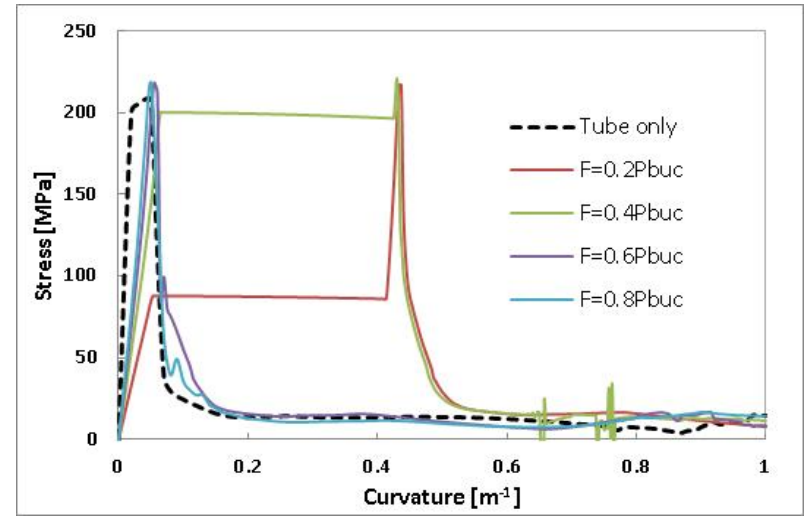

Figure 3. Bending stress comparison of square tube due to damping load of supporting part

Table 3. Bending stress comparison

\begin{tabular}{|c|c|c|}
\hline $\begin{array}{c}\text { Damping Load } \\
\mathbf{F}=[\mathbf{k N ]}\end{array}$ & $\begin{array}{c}\text { Max Bending stress } \\
{[\mathbf{M P a}]}\end{array}$ & $\begin{array}{c}\text { Curvature } \\
{\left[\mathbf{m}^{-1}\right]}\end{array}$ \\
\hline $\begin{array}{c}\text { Square tube without } \\
\text { damper }\end{array}$ & 208.034 & 0.040 \\
\hline $0.2 \mathrm{P}_{\text {buc }}$ & 217.09 & 0.433 \\
\hline $0.4 \mathrm{P}_{\text {buc }}$ & 220.86 & 0.430 \\
\hline $0.6 \mathrm{P}_{\text {buc }}$ & 218.44 & 0.055 \\
\hline $0.8 \mathrm{P}_{\text {buc }}$ & 218.14 & 0.050 \\
\hline
\end{tabular}


From table 3 maximum bending stress obtained at square tube without supporting part and smallest curvature obtained from square tube with damping load $0.8 \mathrm{P}_{\text {buc }}$.

Result of bending on square tube also obtained as image from each curvature condition as seen at table 4. Each damping load produces different deflection and buckling point.

Another result to analyse bending characteristic of square tube is elongation of the supporting part. Figure 4 described elongation and curvature from each damping load.

Table 4. Square tube condition base on damping load

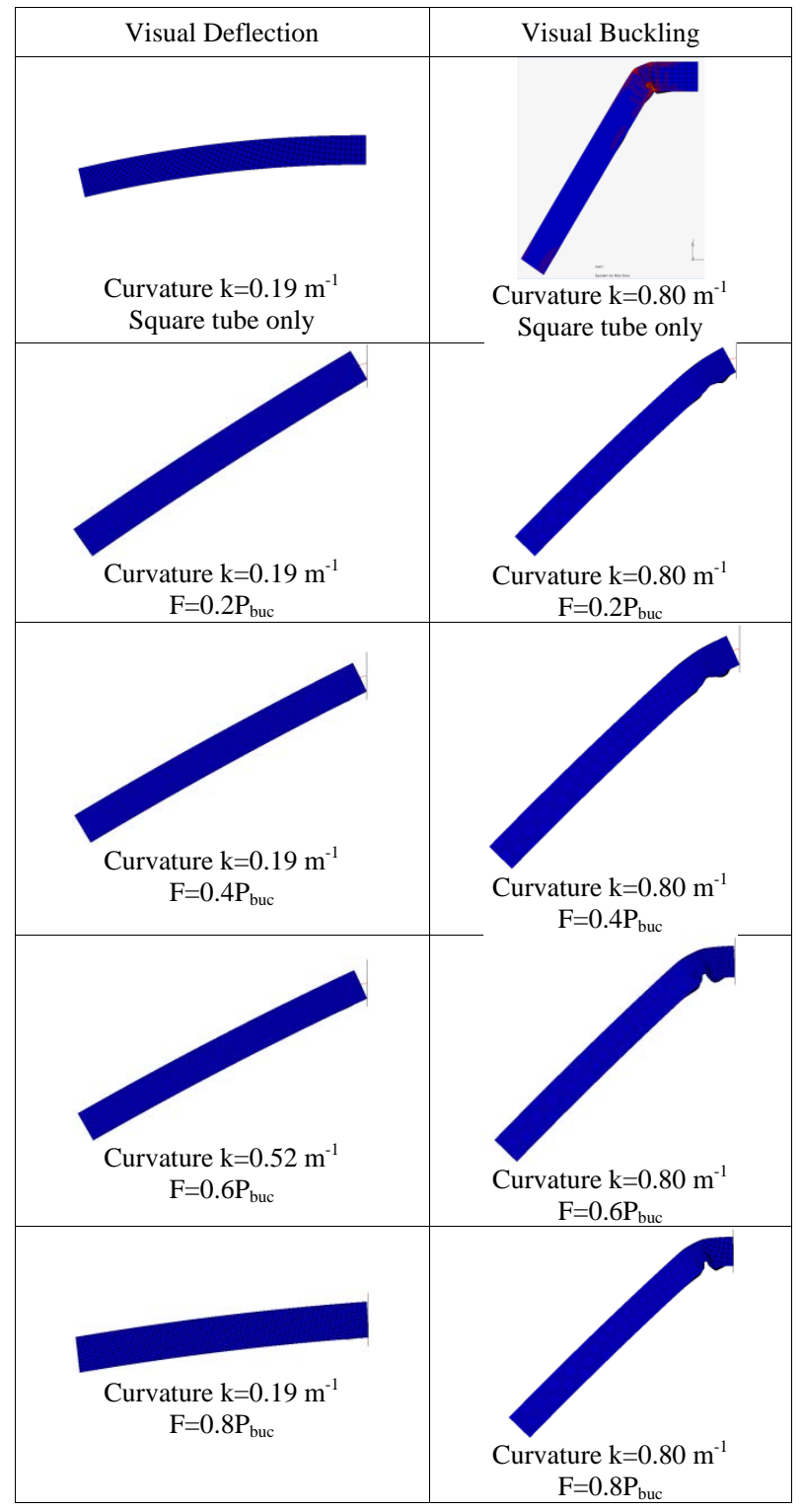

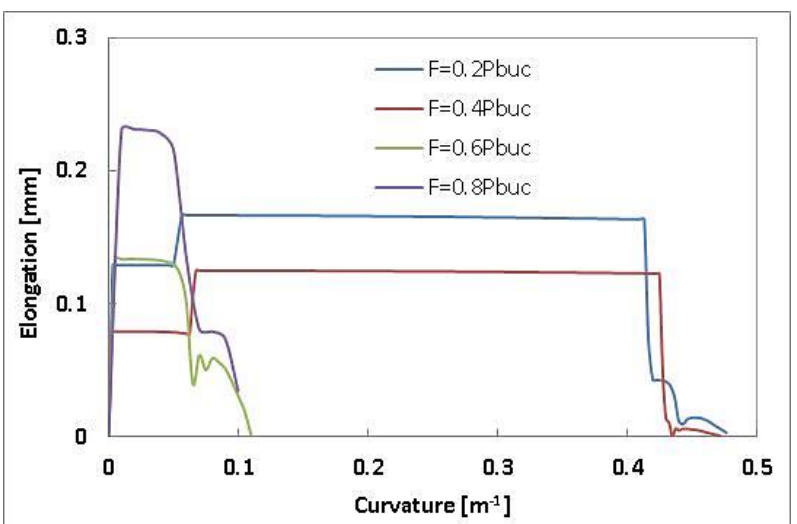

Figure 4. Supporting part elongation and beam curvature

From figure 4 square tube with $\mathrm{F}=0.8 \mathrm{P}_{\text {buc }}$ is longest elongation and tube with $\mathrm{F}=0.4 \mathrm{P}_{\mathrm{buc}}$ is smallest elongation. While square tube only is considered as basic elongation (null) without supporting part.

Table 5. Maximum elongation of supporting part for each damping load

\begin{tabular}{|c|c|c|}
\hline $\begin{array}{c}\text { Damping load } \\
\mathbf{F}=[\mathbf{K N}]\end{array}$ & $\begin{array}{c}\text { Max Elongation } \\
{[\mathbf{m m}]}\end{array}$ & $\begin{array}{c}\text { Curvature } \\
{\left[\mathbf{m}^{-1}\right]}\end{array}$ \\
\hline Square tube only & - & - \\
\hline $0.2 \mathrm{P}_{\text {buc }}$ & 0.166 & 0.476 \\
\hline $0.4 \mathrm{P}_{\text {buc }}$ & 0.125 & 0.472 \\
\hline $0.6 \mathrm{P}_{\text {buc }}$ & 0.133 & 0.110 \\
\hline $0.8 \mathrm{P}_{\text {buc }}$ & 0.231 & 0.100 \\
\hline
\end{tabular}

Geometrical view of buckling point described at table 4 . Buckling is happen at near end-side of square tube with supporting part, otherwise square tube without supporting part has buckling away from end-side of the beam. This condition explained from simulation model. Bending load attached at front side of beam, while bending rotation start load concentrated on all surface. Lower side of beam againts compression stress so the buckling occurs at this surface.

Conversely beam with supporting part can share elongation between beam's surface and supporting part buckling occurred at near end-side of beam and rigid wall. Because of lid thickness of end-side 5 times higher than web, compression stress concentrated at lower side and buckling occurred at this point rather than rear end surface. Contact between supporting part and rigid wall attached at rear-end side. 


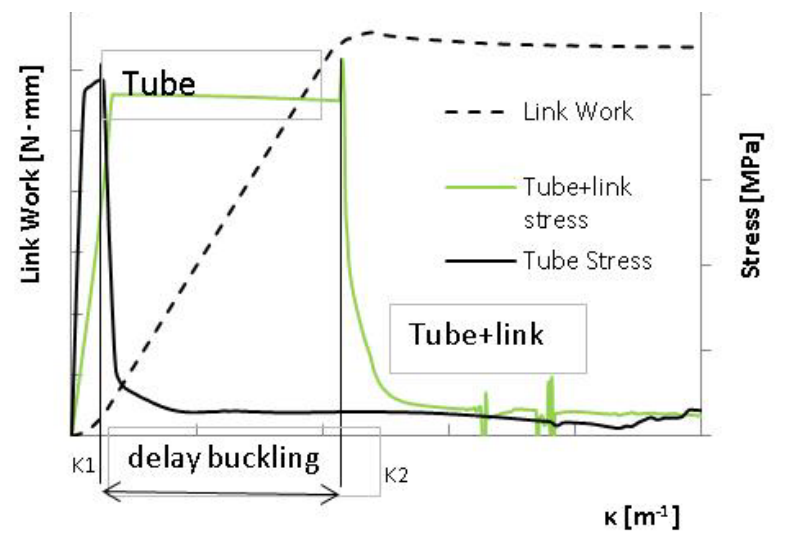

Figure 5. Stress comparison between tube only and with supporting part ( $\mathrm{F}=0.4 \mathrm{Pbuc}$ ).

Figure 5 shows that square tube using supporting part occurred buckling at K2 and square tube only at K1. Those points showed that using supporting part could increase curvature and reduce buckling than square tube without supporting part.

\section{Discussion}

According to result of bending beam it seems that tube without supporting part has lowest bending stress compare to others. It is happen because entire bending stress only restrain by it square tube body and directy contact by bending force. However this condition result high initial bending stress. Compare than square tube with supporting part, they led initial elongation between tube and supporting part. Produce lower initial bending stress and longer elongation. Square tube with supporting part $\mathrm{F}=0.8 \mathrm{P}_{\text {buc }}$ has longest elongation.
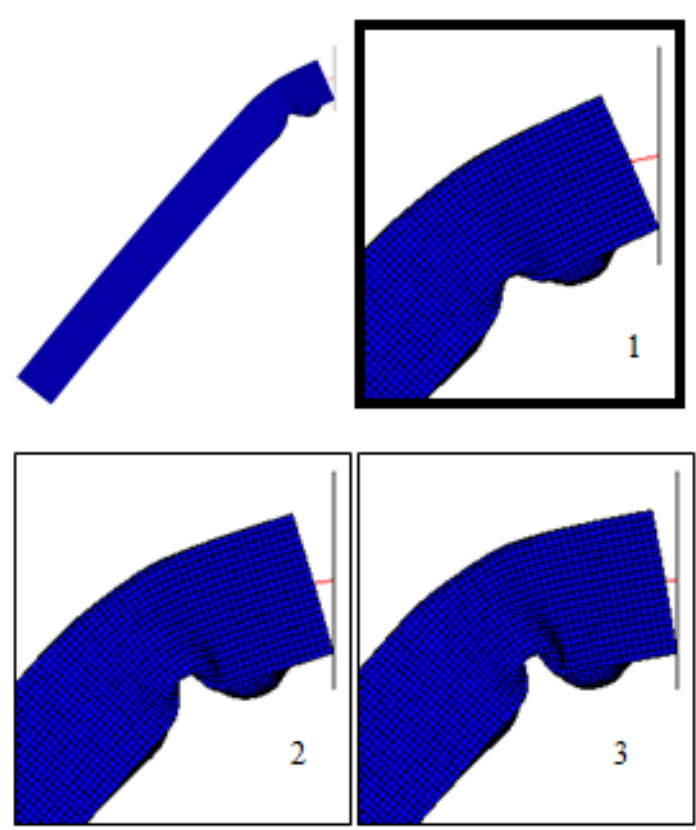

Figure 6. Buckling condition at $\mathrm{F}=0.6 \mathrm{Pbuc}$
Also we obtain from figure 6 the deformation of square tube with supporting part has unique form. Buckling point happen at near lower end-side of beam. This happen due to concentration of compression stress are accumulated at lower end of beam bordering with rigid wall, this could create buckling point at lower end-side of square tube.

Beam with supporting part are obtained increase the curvature and could reduce buckling when choosing optimum damping load. In this research opimum damping load obtained at $\mathrm{F}=0,4 \mathrm{P}_{\text {buc }}$, maksimum bending load also obtained at $\mathrm{F}=0,4 \mathrm{P}_{\text {buc }}$. This beam's setting could divide stress between beam and supporting part produce highest bending stress.

\section{Conclusions}

According to finite element analysis of bending on flexible bridge structure lead the conclusion of this study to:

- $\quad$ Buckling can be reduced by using supporting part which can increase buckling stress resistance of the beam.

- $\quad$ Buckling also obtained delay at longer curvature between beam only and beam equipped with supporting part.

- Supporting part in this research helps to explain characteristic of modified beam when experience bending momen. Supporting part related to spring or damper in structural application.

\section{REFERENCES}

[1] Kecman, D. 1983. Bending Collapse of Rectangular and Square Section Tubes. International Journal of Mechanical Science, Volume 25, No 9-10, pp 623-636.

[2] Wierzbicki, T. Recke, L. Abramowicz, W. Gholami, T. Huang, J. 1994. Stress Profiles In Thin-Walled Prismatic Columns Subjected to Crush Loading - II Bending. Computer and Structures, Volume 51, No 6, pp 625-641.

[3] Shi, W. Li, X, -F. Wang, C, Y. 2016. Bending Of Rectangular Plate With Rotationally Restrained Edges Under A Concentrated Force. Applied Mathematics and Computational, Volume 286, pp 265-278.

[4] Wang, J. Afshan, S. Schillo, N. Theofanous, M. Feldmann, M. Gardner, L. 2017. Material properties and compressive local buckling response of high strength steel square and rectangular hollow sections. Engineering Structures, Volume 130, pp 297-315.

[5] Kim, T H. Reid, S R. 2001. Bending Collapse of Thin-Walled Rectangular Section Columns. Computer and Structures, Volume 79, pp 1897-1911.

[6] Abramowicz, W. 1983. Simplified Crushing Analysis of Thin-Walled Columns and Beams. Engng Trans, volume 29, pp 3-27. 
[7] Goncalves, R. Gamotim, D. 2013. Buckling Behaviour of Thin-Walled Regular Polygonal Tubes Subjected to Bending or Torsion. Thin-Walled Structures, Volume 73, pp 185-197.

[8] Chen, D, H., and Masuda, K. 2016. Rectangular hollow section in bending: Part I - Cross Sectional Flattening Deformation. Thin-walled Structures, Vol. 106, pp. 495-507.

[9] Haruyama, S., Oktavianty, O., Darmawan, Z., Kyoutani, T., and Kaminishi, K. 2016. Study on Energy Absorption Characteristic of Cab Frame with FEM. International Journal of Mechanical, Aerospace, Industrial, Mechatronic and Manufacturing engineering, Vol. 10, No:3, pp. 570-576.

[10] Johnson, A, F. 1973. Bending and Torsion of Anisotropic Beams. International Journal Solids Structures, Volume 9, pp 527-551.

[11] An, X. Gao, Y. Fang, J. Sun, G. and Li, Q. 2015. Crashworthiness Design for Foam-Filled Thin Walled Structures with Functionally Lateral Graded Thickness Sheets. Thin-Walled Structures, Volume 91, pp 63-71.

[12] Ziao, Z. Fang, J. Sun, G. and Li, Q. 2015. Crashworthiness Design for Functionally Graded Foam-filled Bumper Beam. Advances in engineering Software, Volume 85, pp 81-95.

[13] Guarracino, F. and Walker, A. (1999). Energy Methods in Structural Mechanics: A Comprehensive Introduction to Matrix and Finite Element Methods of Analysis. London: Thomas Telford, pp. 307. 